\title{
RECICLAGEM DE RESÍDUO DE MÁRMORE E GRANITO EM MATRIZES POLIMÉRICAS
}

\author{
I. F. SANTOS ${ }^{1}$, O. J. M. PIRES ${ }^{2}$, C, R, SILVA $^{2}$ e J. A. S. SOUZA ${ }^{1}$ \\ ${ }^{1}$ Universidade Federal do Pará, Programa de Pós Graduação em Engenharia de Recursos Naturais da \\ Amazônia \\ ${ }^{2}$ Universidade Federal do Pará, Faculdade de Engenharia Química \\ E-mail para contato: iaraferreira.eq@gmail.com
}

\begin{abstract}
RESUMO - A indústria das rochas ornamentais gera grande quantidade de resíduo sólido anualmente. O objetivo desse trabalho é avaliar a produção de compósitos a partir de resíduos sólidos provenientes do beneficiamento de mármore e granito utilizando resina poliéster isoftálica como matriz agregante. Após a coleta e beneficiamento do resíduo, realizaram-se experimentos variando a quantidade de resíduo na matriz polimérica, adotou-se $0 \%$ de resíduo como padrão de comparação para os demais corpos de prova contendo 10, 20, 30, 40, 50, 60 e 70\% de resíduo em substituição à resina. Após a confecção dos corpos de prova, foram realizados ensaios experimentais para obtenção de valores de massa específica aparente, absorção de água e porosidade aparente para avaliar a influência da quantidade de resíduo nessas propriedades. Os resultados obtidos comprovam a eficiência da incorporação desse resíduo na matriz polimérica para uso como material alternativo e de menor impacto ambiental.
\end{abstract}

\section{INTRODUÇÃO}

O Brasil detém grandes reservas de pedras ornamentais de revestimento (granito e mármore) com os mais variados aspectos estéticos (Moreira et. al., 2003). A indústria de beneficiamento de mármore e granito vem despertando cada vez mais o interesse dos ambientalistas. Atualmente, e em grande parte dos casos, não existe nenhuma preocupação com o meio ambiente, sendo o rejeito jogado diretamente em lagoas e rios, sem nenhum tratamento prévio, o que, apesar de as lamas de serragem não serem consideradas resíduo perigoso (classe I), constitui um sério problema ambiental (Silva, et al., 2005).

O resíduo em forma de lama é constituído principalmente de carbonato de cálcio, um mineral muito utilizado como carga em polímeros para aumentar a estabilidade térmica e dimensional, além de diminuir custo de matéria-prima para confecção de peças plásticas. A utilização da lama residual de marmoraria em polímeros foi colocada em prática visando à diminuição do impacto ambiental, causado tanto pelo descarte da lama como também para procurar uma fonte alternativa de utilização do carbonato de cálcio proveniente de rejeitos (Ferreira e Nunes, 2007). 
$\mathrm{Na}$ literatura são encontrados diversos trabalhos que visam reutilizar esse material para variados fins, entre eles, incorporação em massas argilosas, produção de vidros especiais, cerâmica vermelha, produção de cosméticos, entre outros. Outra alternativa para a utilização do resíduo do mármore e granitos é como carga em compósitos, pois é um resíduo de baixo custo e altamente disponível.

Genericamente, qualquer material consistindo de dois ou mais componentes com propriedades diferentes e contornos distintos entre os componentes pode ser referido como um material compósito. Os compósitos podem ser classificados em dois grupos principais. O primeiro grupo compreende compósitos conhecidos como "materiais enxertados". A principal característica desses materiais é a existência de uma matriz cujas propriedades são aprimoradas pelo enxerto de algumas partículas. O segundo grupo envolve os chamados "materiais reforçados". Os componentes básicos desses materiais (algumas vezes chamados de "compósitos avançados") são fibras longas e finas possuindo alta resistência e dureza. (Oliveira, 2013 apud Vasiliev e Morozov, 2001).

Compósitos de matrizes poliméricas estão sendo bastante utilizados, principalmente quando se trata de aplicações a longo prazo em ambientes hostis, tais como ambientes ácidos ou alcalinos. Dessa forma, é estudada nesse trabalho a possibilidade de uso do resíduo de mármore e granito como carga em uma matriz polimérica.

Cargas são materiais que podem ser adicionados às resinas por diversas razões, ou seja, por oferecer alguma vantagem ao processo, sendo uma das principais a redução dos custos de produção. Em se tratando de um resíduo sem valor comercial e que oferece risco ao meio ambiente, o processo se torna ainda mais vantajoso.

\section{OBJETIVO}

Confeccionar compósitos a partir de resíduo de mármore e granito utilizando uma resina de poliéster insaturado como matriz agregante e avaliar a variação da massa específica aparente, porosidade aparente e absorção de água do material obtido com o aumento do teor de resíduo (carga) em substituição à resina.

\section{MATERIAIS E MÉTODOS}

Para a determinação da massa específica aparente, porosidade aparente a absorção de água do compósito proposto neste trabalho, foram confeccionados corpos cilíndricos de compósitos de poliéster insaturado preenchido com carga de RMG.

\subsection{Materiais}

A resina utilizada, resina AM 910, assim como o acelerador de cobalto e o iniciador MEKP (Butanox M-50), conforme a Figura 1, foram produzidas pela empresa AEROJET Brasileira de 
Fiberglass ltda, bem como o desmoldante Desmoljet. A densidade da resina utilizada apresenta valor médio de $1,14 \mathrm{~g} / \mathrm{cm}^{3}$ (OLIVEIRA, 2013).

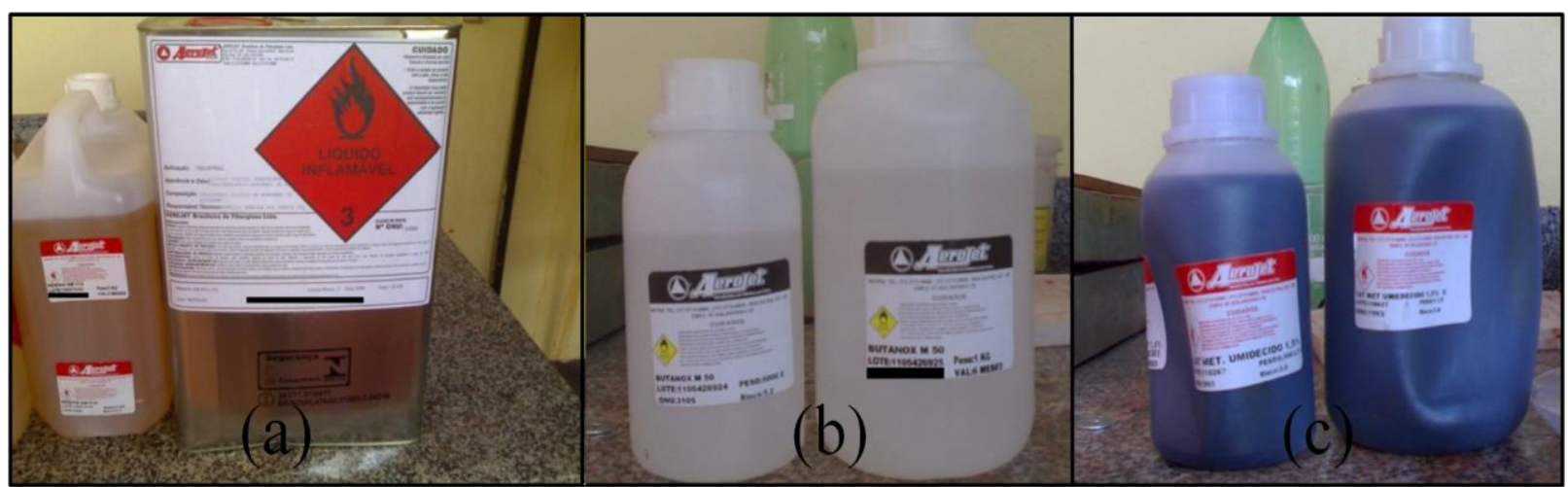

Figura 1- Resina de poliéster insaturado (a), iniciador peróxido de etil-metil cetona (MEK-P) (b) e acelerador de cobalto (c).

O resíduo de mármore e granito foi disponibilizado pela empresa Brilasa Britagem e Laminação de Rochas S/A; após a coleta do material foi realizada a secagem em estufa por aproximadamente 24 horas. Em seguida, o material passou pelo processo de cominuição e peneiramento manual em peneira 100 mesh da série Tyler. A Figura 2 apresenta o material utilizado após o beneficiamento.

Figura 2 - RMG obtido após o beneficiamento.

\subsection{Metodologia Experimental}

Foram realizados cálculos, com base no volume dos corpos de prova, para determinar a quantidade necessária dos materiais acima citados na mistura. Dessa forma, foram utilizados em todos os experimentos 1,0\% de acelerador de cobalto e 1,5\% de Butanox M-50 com base em trabalhos já realizados nessa área, variando nos experimentos os valores de resina e RMG. Os corpos de prova contendo $0 \%$ de RMG foram adotados como padrão de comparação para os corpos de prova contendo o rejeito, sendo assim, foram confeccionados compósitos com 10, 20, 30, 40, 50, 60 e 70\% de carga. Aderiu-se, para bases de cálculo, $10 \%$ de erro para os valores dos materiais, levando-se em conta o 
material perdido em todo o processo de confecção.

Após a pesagem, os materiais foram misturados em um béquer, com o auxílio de um bastão de vidro, em seguida homogeneizados e despejados na forma cilíndrica, que previamente foi umidificada com o desmoldante para facilitar a retirada do compósito após o período de cura. Logo após a mistura atingir o ponto de gel, o material era prensado, com o auxílio de um conjunto de pesos, durante 20 minutos. Transcorrido esse tempo, o material era retirado da forma. A Figura 3 apresenta a forma cilíndrica utilizada para a conformação dos corpos de prova.

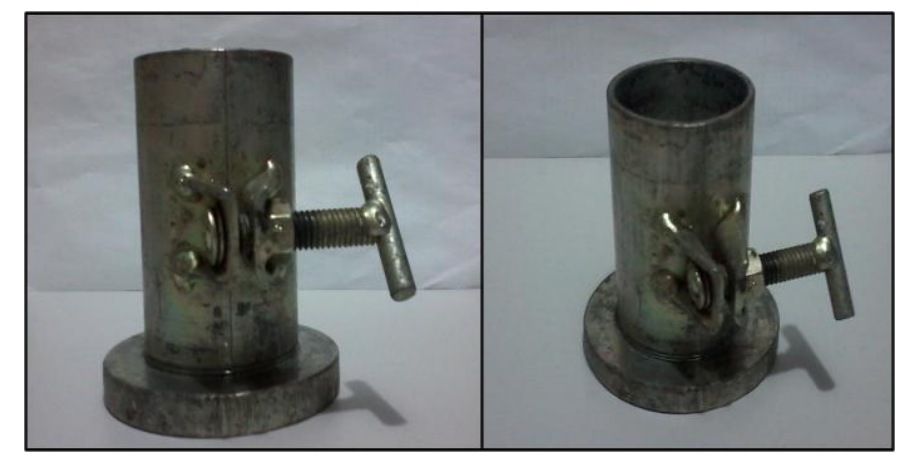

Figura 3 - Forma cilíndrica utilizada para confecção do compósito.

Foram confeccionados cinco corpos de prova para cada mistura, com diâmetro e 4,99 cm e $1 \mathrm{~cm}$ de espessura, para bases de cálculo, os quais podem ser visualizados na Figura 4.

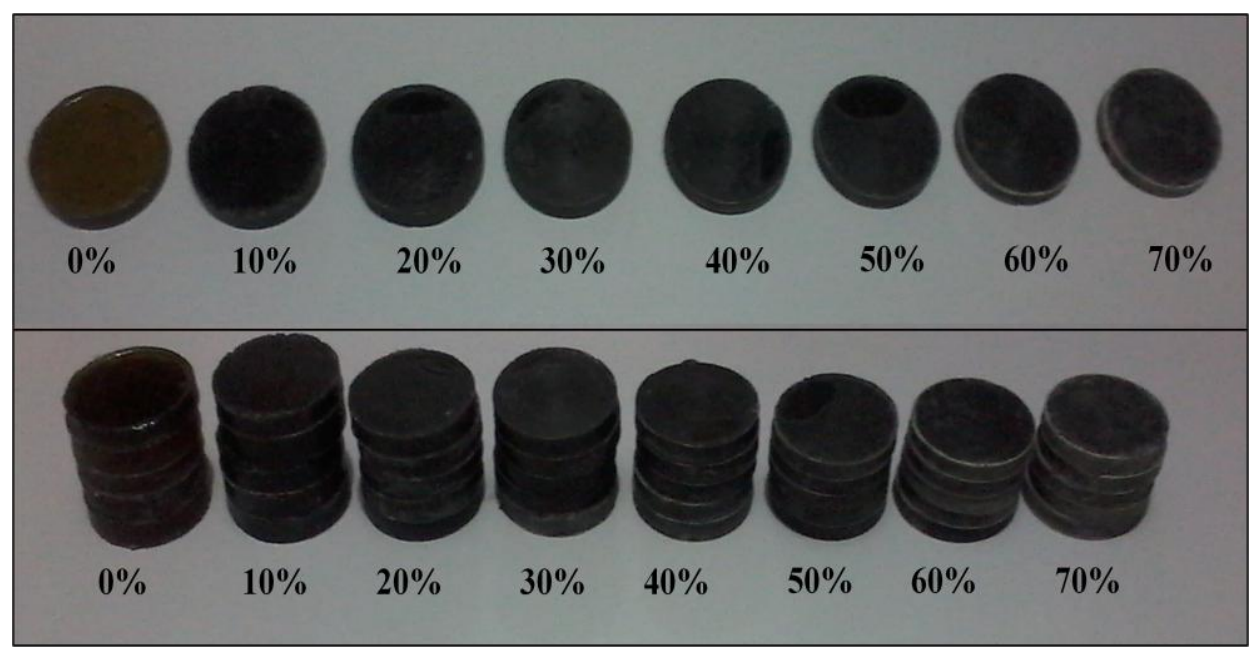

Figura 4 - Corpos cilíndricos obtidos após as misturas realizadas.

Para realização dos testes de MEA, PA e AA, fez-se necessário obter os valores de massa seca, massa úmida e massa imersa de cada um dos corpos cilíndricos confeccionados para cada mistura. Para obtenção dos valores de massa imersa e massa úmida foi necessário deixar os 
compósitos imersos em água por um período de 24 horas. De posse dos valores mássicos, fez-se uso das seguintes Equações 1, 2 e 3 para a obtenção dos valores das propriedades dos materiais obtidos:

$$
\begin{aligned}
& M E A=\frac{M_{S}}{\left(M_{U}-M_{I}\right)}\left(\mathrm{g} / \mathrm{cm}^{3}\right) . \\
& P A=\frac{\left(M_{U}-M_{S}\right)}{\left(M_{U}-M_{I}\right)} \times 100(\%) . . \\
& A A=\frac{\left(M_{U}-M_{S}\right)}{M_{S}} \times 100(\%) . .
\end{aligned}
$$

Sendo:

$\mathrm{M}_{\mathrm{S}}$ : Massa seca; $\mathrm{M}_{\mathrm{U}}$ : Massa úmida; $\mathrm{M}_{\mathrm{I}}$ : Massa Imersa.

\section{RESULTADOS E DISCUSSÃO}

\subsection{Umidade}

Antes de ser submetido à secagem, foi determinada a umidade do material coletado, o valor encontrado foi de $32,3 \%$.

\subsection{Difração de Raios-x}

A caracterização do RMG foi feita também por meio de difração de raios-x. A Figura 5 apresenta o difratograma do resíduo utilizado nesse trabalho.

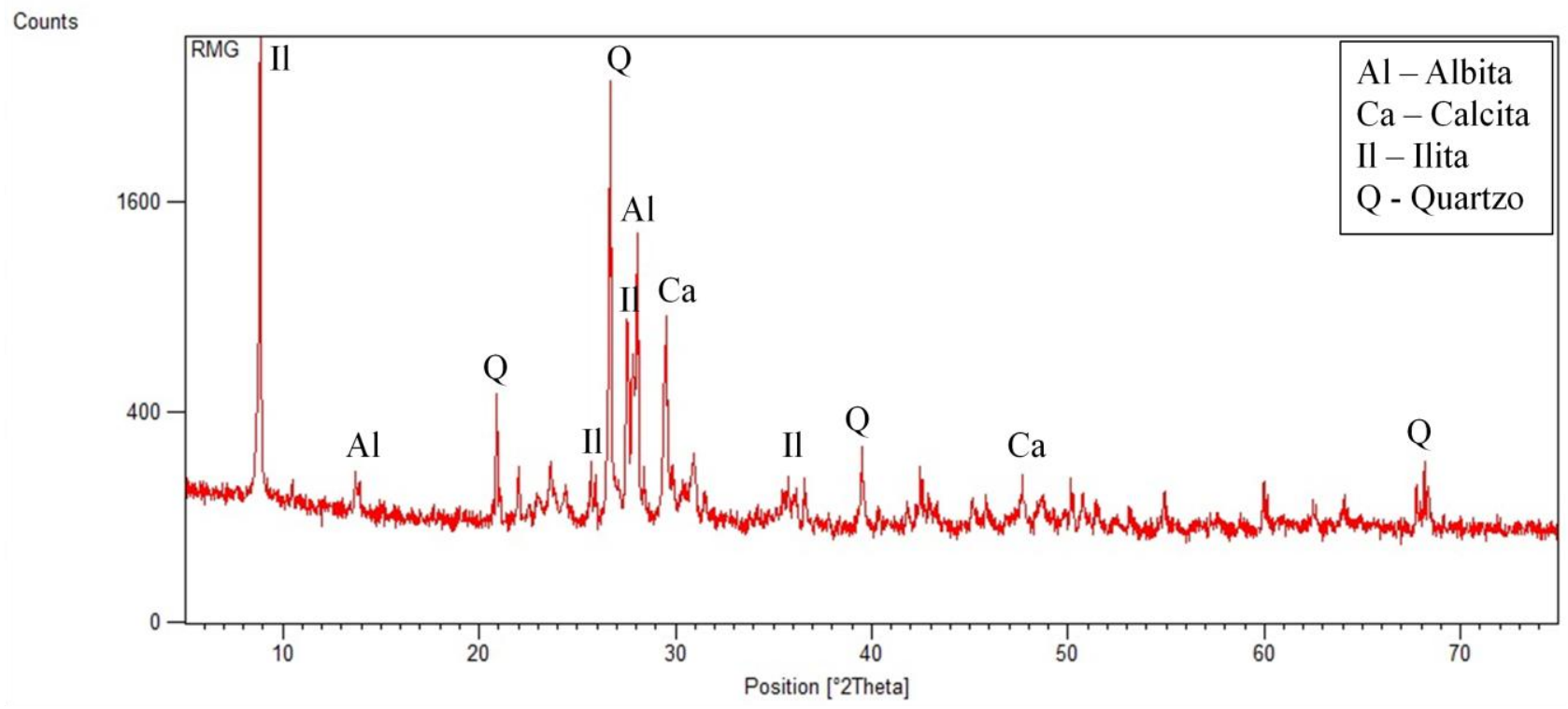

Figura 5 - Difratrograma do resíduo de mármore e granito. 
De acordo com o difratograma, observa-se a presença predominante dos minerais albita $\left(\mathrm{NaAlSi}_{3} \mathrm{O}_{8}\right)$, calcita $\left(\mathrm{CaCO}_{3}\right)$, ilita $\left(\mathrm{Al}_{3} \mathrm{H}_{2} \mathrm{KO}_{12} \mathrm{Si}_{3}\right)$ e quartzo $\left(\mathrm{SiO}_{2}\right)$.

\subsection{Massa Específica Aparente}

Através da Equação 01, foi calculado o valor de MEA de cada corpo de prova, e em seguida encontrado o valor médio para cada mistura. A Figura 6, apresenta o gráfico obtido a partir da comparação dos valores para as variadas misturas.

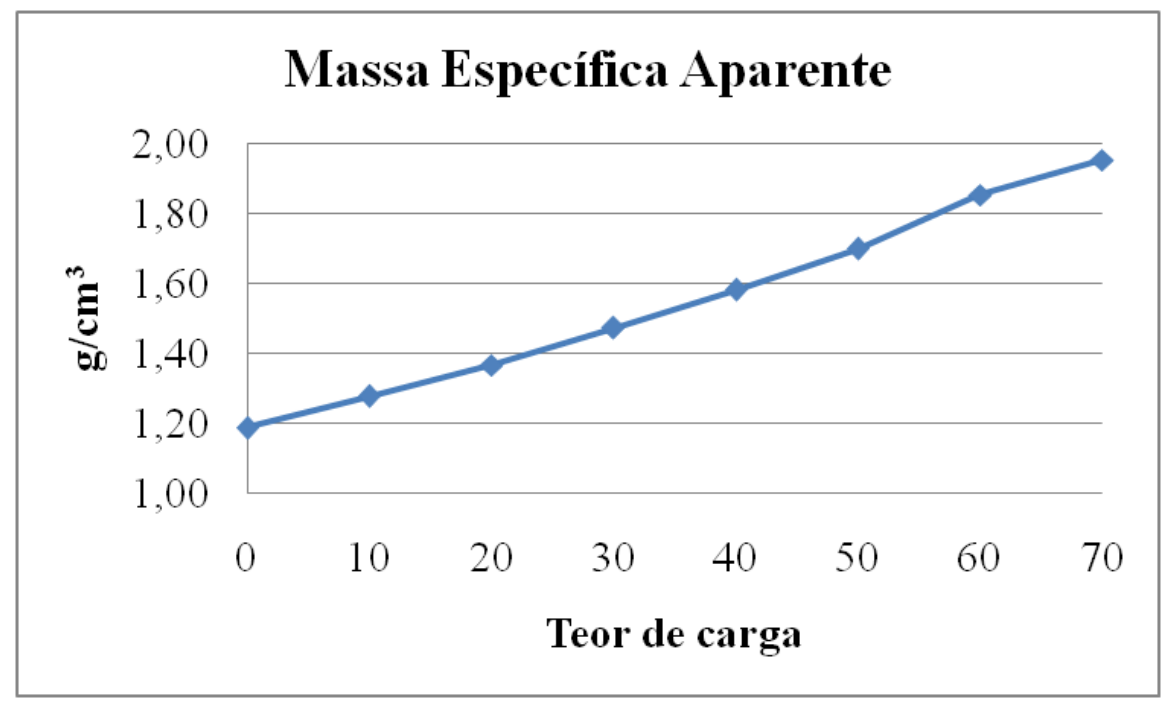

Figura 6 - Gráfico da variação da MEA em função do teor de resíduo no compósito.

Como observado na Figura 6, o aumento do teor de resíduo na mistura do compósito acarreta no aumento da MEA do corpo de prova, devido ao valor da densidade do RMG ser superior ao valor da densidade da resina.

\subsection{Porosidade Aparente e Absorção de Água}

Fazendo-se uso das Equações 02 e 03, foram obtidos os valores da PA e AA média para cada experimento. As Figura 7 e 8, apresentam os gráficos obtidos a partir da comparação dos valores percentuais dessas duas propriedades em função do teor de RMG na mistura. 


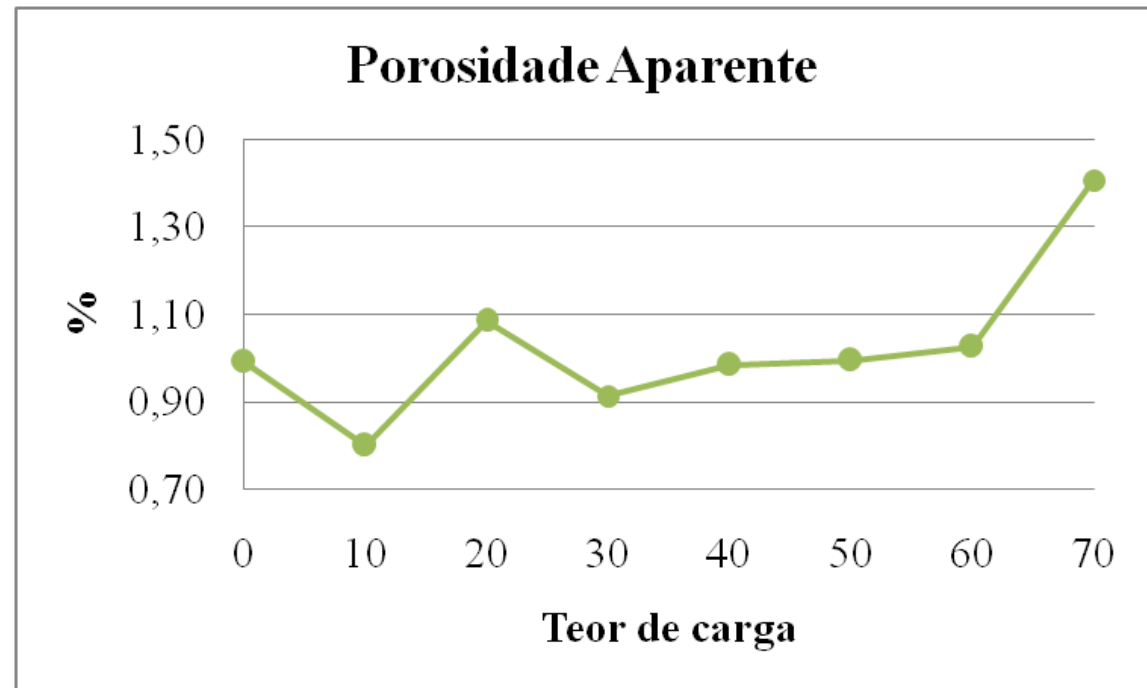

Figura 7 - Gráfico da variação da PA em função do teor de resíduo no compósito.

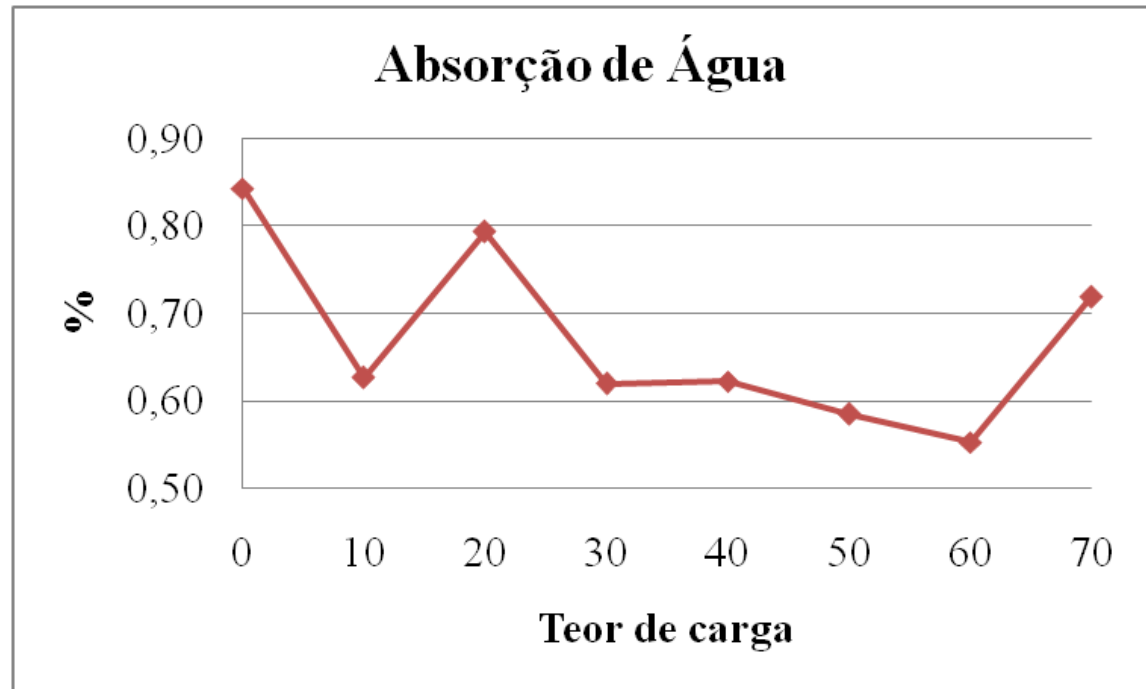

Figura 8 - Gráfico da variação da AA em função do teor de resíduo no compósito.

Como observado nos gráficos apresentados nas Figuras 7 e 8, essas duas propriedades estão diretamente ligadas, pois uma maior porosidade aparente implica em maior absorção de água. No entanto, é notável que em algumas misturas foram obtidos valores acentuados dessas propriedades, como nas misturas com 10, 20 e 70\% de resíduo na mistura. Portanto, analisando os gráficos observase que essas propriedades são consideravelmente sensíveis quanto à variação do teor de carga na mistura. Como essas propriedades estão relacionadas ao espaço de vazios presentes no interior do compósito, deve-se levar em consideração não somente os espaços entre as partículas do sólido, mas também o espaço gerado pelo desprendimento de ar inserido na mistura a partir da agitação da mesma. Devido aos valores variáveis das propriedades PA e AA, faz-se necessário um estudo mais profundo quanto à sensibilidade dessas propriedades com o teor de carga presente no compósito. 


\section{CONCLUSÃO}

Os corpos de prova confeccionados mostraram ser possível a incorporação desse resíduo para confecção de compósitos que possam ser empregados para substituição de materiais em áreas como a indústria da construção civil, no entanto, faz-se necessário um estudo para definir qual a maior quantidade de resíduo que pode ser incorporada dependendo das normas vigentes para o material que será substituído, bem como testes de resistência a flexão e compressão.

Após a realização dos experimentos, notou-se que apenas o experimento com $70 \%$ de carga apresentou certa dificuldade para conformação na forma, contudo, podem ser estudadas novas formas de homogeneizar com maior facilidade as misturas para essa quantidade. Dependendo do uso que será dado ao material, é interessante que ocorra um polimento para melhor acabamento da superfície.

\section{NOMENCLATURA}

RMG - Resíduo de mármore e granito

AA - Absorção de água

PA - Porosidade aparente

MEA - Massa específica aparente

\section{REFERÊNCIAS}

FERREIRA, A. C. B.; NUNES, E. C. D. Reaproveitamento e incorporação de resíduo de mármore em poliamida 66. 2007.

MOREIRA, J. M. S.; FREIRE, M. N.; HOLANDA, N. F. Utilização de resíduo de serragem de granito proveniente do estado do Espírito Santo em cerâmica vermelha. Cerâmica, v. 49, p. 262-267, 2003.

OLIVEIRA, M. J. A. Efeito da adição de lama vermelha como carga nas propriedades ecânicas de compósitos de poliéster insaturado reforçado com fibra natural de curauá (Ananas erectifolius). 2013. Dissertação (Mestrado em Engenharia Química) - Universidade Federal do Pará. Belém, 2013.

SILVA, J. B.; HOTZA, D.; SEGADÃES, A. M.; ACCHAR, W.Incorporação de lama de mármore e granito em massas argilosas. Cerâmica, v. 51, p. 325-330, 2005. 